\title{
A ANÁLISE DAS ESTRATÉGIAS DE INOVAÇÃO EM EMPRESAS DO COMPLEXO EMPRESARIAL INTEGRADO DE TOBIAS BARRETOISE
}

\author{
THE ANALYSIS OF INNOVATION STRATEGIES IN COMPANIES OF THE INTEGRATED \\ COMPANY OF TOBIAS BARRETO / SE
}

\section{Thiago Farias da Silva}

Bacharel em Administração pela Universidade Federal de Sergipe, 2016. Graduando em Ciências Contábeis pela Universidade Federal de Sergipe, Brasil.

\section{Alef Menezes dos Santos}

Mestrando em Ciência da Computação pelo Programa de Pós-Graduacão em Ciência da Computação (PROCC) pela Universidade Federal de Sergipe, Brasil.

\section{Marcos Eduardo Zambanini}

Doutor em Administração pela USCS, 2014. Mestre em Administração pela USCS, 2014. Bacharel em Administração de empresas pela USCS, 2005. Professor concursado adjunto da Universidade Federal de Sergipe (UFS), Brasil.
Data de recebimento: 21/08/2017 Data de aceite: 17/05/2018

\section{RESUMO}

O objetivo deste estudo foi analisar as micro e pequenas empresas têxteis no Complexo Empresarial Integrado do Município de Tobias Barreto/SE, visando conhecer as estratégias de inovação e os acordos de cooperação entre estas. Especificamente trata de: apontar as estratégias de inovação adotada, elencar as atividades compartilhadas e verificar as vantagens competitivas advindas da cooperação para as empresas associadas. Quanto à metodologia, o estudo tem como característica pesquisa exploratória. Os dados foram coletados por meio de entrevista com roteiro semiestruturado tendo 14 proprietários de empresas de micro e pequeno porte. Os resultados apontam para estratégias basicamente de sobrevivência, onde as inovações adotadas se baseiam em diferenciação ou melhorias nos produtos. Existe a cooperação entre empresas baseada, apenas, em interesses pessoais, que as impede de alcançar benefícios maiores e duradouros. Entre as vantagens conquistadas estão, o poder de barganha, a redução de custos, o compartilhamento de informações e o aprendizado.

Palavras-chave: Inovação. Acordos de Cooperação. Micro e Pequenas Empresas

\section{ABSTRACT}

The objective of this study was to analyze the micro and small textile companies in the Integrated Business Complex of Tobias Barreto/ SE, in order to know the innovation strategies and the cooperation agreements between them. Specifically it approaches: point out the innovation strategies adopted; to quote the shared activities attempting to the competitive advantages of cooperation for member companies. Regarding the methodology, the study has as exploratory research characteristic. The data were collected through a semi-structured interview with 14 owners of micro and small companies. The results point to basically survival strategies, which the adopted innovations are based on differentiation or improvement of products. There is acooperation between companies just based in personal interests, which prevents them from achieving greater and lasting benefits. Among the gained advantages are bargaining power, cost reduction, the sharing information and the learning.

Keywords: Innovation. Cooperation Agreements. Micro and Small Companies. 


\section{INTRODUÇÃO}

Mesmo tendo um elevado percentual de mortalidade e desafios para manterem-se ativas, as micro e pequenas empresas (MPEs) mostraram serem importantes geradoras de emprego no Brasil. Semelhantemente aos demais segmentos da economia brasileira, estas passaram por uma diminuição expressiva devido à crise instalada no país. Todavia, se comparadas às médias e grandes empresas, as quais tiveram 896,5 mil postos de trabaIhos fechados, as MPEs sustentaram um saldo de 65,8 mil vagas em 2015 (SEBRAE, 2015).

As MPEs também são as responsáveis por mais da metade dos empregos com carteira assinada do Brasil. Este fato, somado à ocupação que os empreendedores geram para si, possibilita dizer que os empreendimentos de micro e pequeno porte são responsáveis por, pelo menos, dois terços do total das ocupações existentes no setor privado da economia (SEBRAE, 2011).

Cabe ressaltar que, em razão do porte e recursos limitados, as MPEs apresentam poucas condições para buscarem sozinhas as vantagens competitivas necessárias para garantir sua sobrevivência e prosperidade (COSTA, 2014). Uma solução para alavancá-las, tem sido a consolidação de acordos colaborativos sejam formais ou informais, o que exige medidas diferentes daquelas usadas com a concorrência tradicional (MINTZSBERG et al.,2007).

Em setores de forte concorrência, é perceptível que as MPEs apresentam diversas restrições para competir isoladamente. Portanto, acordos de colaboração podem representar para estas, um meio de potencializar as chances de sucesso e atingir seus objetivos (NASCIMENTO, 2014). Em- basados nas iniciativas dos segmentos industriais e apoiados nas políticas diferenciadas de preços para grandes volumes de compra, as MPEs começaram a se unir a fim de usufruir dos benefícios advindos das compras em grande escala e do poder de barganha junto aos seus fornecedores.

Essa cooperação consiste no trabalho conjunto entre pessoas e organizações compartilhando: conhecimento, esforços e recursos sejam financeiros, tecnológicos ou mercadológicos, visando o alcance comum de objetivos (BALESTRIN; VERSCHOORE, 2008). A partir dessas primeiras parcerias, começaram a se estruturar outros tipos de alianças estratégicas. Essas alianças visavam não apenas a redução de custos nos processos de compra, mas também a aquisição de conhecimento, informação, tecnologia e outras fontes que pudessem se constituir em vantagens competitivas (PACAGNAN, 2006).

Dentre os vários municípios brasileiros que possuem MPEs, pode-se citar o município de Tobias Barreto/SE, localizado no agreste sergipano, conhecido nacionalmente como a Terra dos Bordados. A principal atividade econômica do município está ligada ao setor Têxtil e de Confecções. Este setor é responsável pelo sustento da maior parte das famílias da sede e povoados do município. Isto corrobora para a atenção especial que o setor merece, visto que seu enfraquecimento influencia diretamente na receita do município. As principais peças fabricadas no setor de confecções presente em Tobias Barreto/ SE são: vestuários em geral, cama, mesa, banho e artigos de recém-nascido. Em função do progresso das atividades industriais do município, o Governo do Estado de Sergipe cedeu aos empresários, um espaço de 86.221,93 $\mathrm{m}^{2}$ que serviu para a construção do Complexo Empresarial Integrado, que abri- 
gam 31 galpões, centro de comercialização, centro vocacional tecnológico e centro de serviços.

Constatada a importância das MPEs e sua fragilidade, não diferente nestas citadas o município de Tobias Barreto/se, pretendeu-se neste estudo: apontar as estratégias de inovação adotadas na gestão destas empresas, identificar acordos de cooperação entre as empresas no Complexo Empresarial Integrado, descrever as vantagens competitivas alcançadas pela presença no complexo e elencar as atividades compartilhadas.

Este trabalho está estruturado em 5 seções. A primeira, denominada Introdução, apresenta a contextualização do tema, demonstrando a importância e justificando este trabalho, assim como o objetivo dessa pesquisa. A segundaseção, Fundamentação Teórica, tem o objetivo de trazer os temas pertinentes a essa pesquisa, elaborada a partir de publicações e pesquisas anteriores, abrangendo temas como inovação, alianças entre empresas e possíveis vantagens e benefícios que a cooperação entre elas pode trazer. Em uma terceira, é apresentada a metodologia que norteou esta pesquisa. Na quartaseção são apresentados os resultados, e também é feita uma discussão acerca dos principais achados da pesquisa empírica. Na quinta e última, são destacadas as considerações finais do trabalho.

\section{FUNDAMENTAÇAO TEÓRICA}

Para a sustentação teórica deste artigo, optou-se em desenvolver algumas perspectivas que envolvem a problemática proposta. A contextualização envolve os conceitos de Inovação em MPEs; Alianças Estratégicas, seus tipos e vantagens competitivas advindas por meio desta estratégia.

\subsection{INOVAÇÃO NAS MICRO E PEQUENAS EMPRESAS (MPES)}

Ainda que as MPEs tenham papel importante na economia brasileira, a taxa de mortalidade entre elas é significativa. De acordo com Brasil (2012), 58\% das empresas de pequeno porte fecharam as portas antes de completarem cinco anos em 2010. Em depoimento ao ocorrido, empreendedores descreveram que: capital; falta de clientes; impostos; burocracia e concorrência são os principais motivos para o acontecido.

Porter (1999) argumenta que a concorrência é um desperdício: conduz a duplicação de esforços e impede que as empresas atinjam economias de escala. Quando estas se envolvem em rixas acirradas, competem não apenas pela participação no mercado, mas também por pessoas, excelência técnica e pelo direito de ser consideradas como as melhores. Em contrapartida, afirma que a rivalidade é o fator mais importante na criação de vantagem competitiva, em razão do poderoso efeito estimulante sobre os demais. As empresas são obrigadas a irem além dos benefícios, e, como consequência, conquistam vantagens mais sustentáveis (PORTER, 1999).

A concentração geográfica amplifica o poder da rivalidade local. Esse fator aumenta a pressão pela melhoria e diminui os tipos de vantagem provenientes de localização. Este é o caso do município de Tobias Barreto, devido o número significativo de empresas do mesmo segmento alocadas no município. Alguns estudos comprovam a importância de que haja cooperação entre as empresas da localidade em prol de ganho de competitividade e redução da rivalidade, promovendo ganhos coletivos. Costa (2014) verificou que os albergues da 
cidade de Belo Horizonte tratam seus negócios de maneira isolada sem nenhum relacionamento com os concorrentes. Como consequência disso, eles não possuem nenhuma representatividade nem gozam de vantagens advindas da cooperação, apesar de julgar importante. Por outro lado, os gestores dos supermercados da cidade de Parobé-RS estudados por Nascimento e Schreiber (2014) devido à grande concorrência e competitividade no setor, julgaram muito importante a formação de alianças para que houvesse uma oferta mais justa de serviço.Nesse ambiente existem quatro maneiras pelas quais uma empresa pode ampliar seu poder competitivo: com atividades internas; com aquisições; por meio de transações formais e distantes; e com alianças estratégicas. A melhor abordagem dependerá dos recursos envolvidos e do controle (LEWIS, 1992). Neste contexto, a inovação surge como alternativa de elevar a competitividade das MPEs.

Apesar da importância para o dinamismo econômico, as MPEs enfrentam certas dificuldades relacionadas ao custo de treinamento de mão de obra, custo de participação em feiras, acesso à linha de crédito e obtenção de melhores condições na aquisição de matéria prima (SACRAMENTO; BARBOSA, 2012). Todas essas dificuldades corroboram para a elevada taxa de mortalidade entre estas.

A estratégia de inovação também é recomendada para solucionar problemas simples de crescimento dos produtos em setores maduros, excesso de disponibilidade, de recursos e riscos apresentados pelo mercado atual (TAVARES, 2005). Mesmo as pessoas imaginando inovação sendo apenas mudanças radicais, ou exclusivamente tecnológicas, esta pode ser incremental nos produtos, processos e/ou serviços. O motivo que leva a inovar é, em grande parte, substituir as expectativas incertas e os esforços voluntários por estabilidade e rotina. Os procedimentos padrões não são inimigos das empresas, mas sim a sua essência (MINTZBERG et al., 2007).

De acordo com Schumpeter (1912 apud AMORIM; ANDRADE JUNIOR, 2011). O conceito de inovação envolve os seguintes fatores: introdução de um novo produto, sendo para novos consumidores ou com qualidade melhorada para um produto já existente; desenvolvimento de um novo método de produção, ainda não testado no setor onde a empresa atua; abertura de novo mercado, em que outras empresas do setor ainda não tenham entrado; conquista de nova fonte de insumos, sendo que essa fonte já pode existir ou ter sido criada; estabelecimento de uma organização industrial seja a criação de um monopólio ou a fragmentação do mesmo.

Em sua teoria, Christensen (2012) defende a ideia de que empresas estabelecidas em um mercado têm alta probabilidade de vencer novos concorrentes quando a disputa de baseia em inovações progressivas e sustentáveis. Em contrapartida, se os clientes estiverem a buscar soluções mais baratas ou produtos e serviços mais convenientes, a empresa estabelecida tende a perder aos novos concorrentes.

Assim, cabe às MPEs compreenderem inovação não sendo algo puramente tecnológico. Realizar investimentos contínuos em inovação é promover o desenvolvimento de novos, ou melhorias, nos produtos e processos, praticar a gestão da inovação. Realizar ações para capacitação contínua do seu corpo técnico tende a estreitar os relacionamentos com as universidades e os centros de pesquisa, além de terem mais chances de ser inovadoras do que as demais (SILVA NÉTO; TEIXEIRA, 2011). 
A estratégia de inovação incluindo novos processos e padrões tecnológicos, além da busca maior de flexibilidade, constitui um caminho possível para que as MPEs possam se inserir no mercado atual de demandas instáveis e diferenciadas (GOMES; BARBOSA, 2012). Outro fato sobre a inovação tecnológica, é que a mão de obra, antes manufaturada, passa a ser substituída pela força de trabalho nas máquinas modernas, que dispensa quantidade e busca qualificação na mão de obra. Outra maneira de inovar seria a aderindo a inovação sustentável, que consiste em aperfeiçoar os produtos que, historicamente, são mais valorizadas pelo cliente (CHRISTENSEN; 2012). Um dos fatores da nova economia mundial é o desafio de inovar constantemente, porém, é importante salientar que as empresas não inovam sozinhas; fontes de conhecimento e geração de inovações se situam dentro e fora das organizações (GOMES; BARBOSA, 2012). Além disso, independente do porte da empresa, parcerias estratégicas têm surgido com o objetivo de alcançar inovação.

\subsection{ALIANÇAS ESTRATÉGICAS}

Nesta era de alianças, ter um foco concentrado é imperativo para se atrair parceiros. A melhor maneira de combinar recursos internos e externos é comparando ao mesmo tempo as alternativas possíveis. Inclua combinações com terceiros que aumentem as receitas, reduzam os custos, dividam os riscos ou liberem os recursos internos para atividades mais críticas (LEWIS, 1992).

A necessidade de entender melhor as alianças estratégicas é cada vez mais clara. Se todos os mercados fossem igualmente acessíveis, todas as gerências igualmente habilidosas, todas as informações imediatamente disponíveis e todos os balanços igualmente sólidos, haveria pouca necessidade de colaboração entre os concorrentes (MINTZBERG et al., 2007).

Na atualidade alianças estratégicas são formadas diariamente entre empresas nacionais e/ ou internacionais. O modelo dessas alianças pode variar em função do prazo, da cooperação, e do investimento (LORANGE; ROOS, 1996). Define-se aliança estratégica como Empreendimentos de risco ao longo de uma escala contínua entre, de um lado, transações em um mercado livre (mercado) e, de outro, a internalização total (hierarquia) (LORANGE; ROOS, 1996).

Entende-se como importante que se avalie criticamente, desde o início, os benefícios advindos das alianças para cada parte dos interessados. Doravante, se a aliança estratégica parecer não ter condições de produzir os benefícios visados, as negociações devem, provavelmente, ser interrompidas.

\subsubsection{Tipos de alianças estratégicas}

Embora muitas Alianças envolvam acordos formais, nem sempre é necessário um contrato (LEWIS, 1992). Muitos tipos de acordos, associativismo e parcerias podem ser considerados alianças estratégicas (CASADEl; FARAH; GIULIANI, 2005). Diante da literatura que defini os tipos de alianças, desde acordos informais a join venture, o autor Eiriz (2002) reuniu diversos estudiosos do tema e sugeriu um modelo baseado nos seguintes elementos: atores, atividades e recursos que as empresas envolvem nesta colaboração. Esses elementos, usados outrora no estudo das relações empresariais à luz do paradigma das redes industriais (HAKANS- 
SON, 1982; FORD, 1997apuí EIRIZ, 2002). Segundo o mesmo autor, atores são representados por empresas do mesmo ramo de negócio, clientes e principais fornecedores; atividades se dão quando os atores criam, trocam, desenvolvem ou combinam recursos; recursos são os meios utilizados pelos atores no desenvolvimento de suas atividades.

Nesse sentido, Eiriz (2002) sugere 16 tipos de alianças estratégicas. Os Quadros 1, 2 e 3 revelam cada tipo de acordo com o domínio da cooperação:

Quadro 1 - Tipos de alianças estratégicas do domínio financeiro

Tipo

Aquisição de empresa
Descrição

Ocorre quando uma empresa adquire uma posição majoritária no capital de outra empresa.

Participação minoritária em Verifica-se quando uma empresa adquire uma posição inferior a $50 \%$ do capital empresa de outra empresa.

Join venture

Verifica-se quando duas ou mais empresas constituem apenas uma nova entidade.

Fusão

Representa o grau máximo de integração de duas ou mais empresas que decidem fundir as suas estruturas de capitais em uma única unidade.

Fonte: Adaptado de Eiriz (2002)

As alianças apresentadas no Quadro 1, do domínio financeiro, são alianças que ocorrem quando há relações financeiras envolvidas, ou seja, as empresas fazem alianças embasadas em interesses financeiros mútuos. Porém, para o autor, "a inclusão das fusões e aquisições é uma opção questionável pois, nestes casos, a autonomia de um dos parceiros desaparece e, em certa medida, deixa de haver uma aliança" (EIRIZ, 2002, p. 74).

Quadro2 - Tipos de alianças estratégicas do domínio comercial

Tipo

Grupo de exportadores

Acordos de distribuição

Acordo de representação

Central de compras
Descrição

Conjunto de empresas do mesmo setor que cooperam para desenvolvimento dos mercados externos. A cooperação está em estudo de mercado externo, participação em feiras, publicidade, além do poder de barganha e do maior gama de produtos.

Estabelece-se com produtores de bens finais e outras empresas de domínio ou distribuição ao consumidor final.

Verificam-se quando uma empresa de torna a representante dos produtos e marcas da outra empresa para determinado mercado.

Por meio da cooperação na compra elas podem conquistar poder de escala e adquirir maior poder de negociação junto a fornecedores não só em preços, mas em condições de pagamento, qualidade e condições de entrega. 
Franquia

\section{Assistência comercial}

Fonte: Adaptado de Eiriz (2002)
No Quadro 2 são apresentadas as alianças do domínio comercial. Neste tipo de aliança, apesar dos interesses dos envolvidos serem deste domínio, ou seja, a busca de ganho coletivo por meio de acordos comerciais que proporcionem vantagem para todos, para que seja considerada aliança estratégica, deve envolver e afetar todas as atividades da empresa, não somente as atividades comerciais, de forma estratégica. Para que esse tipo de aliança ocorra, é necessário que haja cooperação e confiança entre os envolvidos.
Quadro 3 - Tipos de alianças estratégicas do domínio técnico/produção

\section{Tipo}

Descrição

Esta modalidade se estabelece entre duas ou mais empresas que possuem

Consórcio capacidades e competências susceptíveis de poder de complementar no desenvolvimento de um projeto técnico de grande envergadura e duração no tempo.
Formação e/ou assistência técnica
Ocorre em maior frequência em setores em que a base tecnológica é importante. O acordo pode ultrapassar o objetivo e resultar na formação de mão de obra entre outras qualificações.

\section{Subcontratação}

Neste tipo uma empresa subcontrata a outra parte do seu processo de produção. Deste modo, cada um dos parceiros desenvolve trabalho diferente.
Acordo de produção conjunta
Quando duas empresas produzem conjuntamente os mesmos produtos para satisfazer as necessidades de mercado, as quais não conseguiam responder individualmente por falta de capacidade.

\section{Acordo de investigação e desenvolvimento}

Verifica-se particularmente em setores da atividade onde a investigação e desenvolvimento de novos produtos e processos assumem um peso muito importante. Dividir custos fixos é o principal foco

\section{Licenciamento de parceiros}

Aliança estratégia onde uma empresa cede paraa outra os direitos de exploração de uma patente, produto ou processo fabrico mediante compensação geralmente financeira. 
Da mesma forma que ocorre nas alianças estratégicas do domínio comercial, as alianças do domínio técnico/produção, apresentadas no Quadro 3, necessitam que as ações coletivas atinjam toda a empresa, de forma estratégica.

Ou seja, nem todos os acordos com entidades formadoras ou prestadoras de assistência técnica são alianças estratégicas; só o são aqueles acordos que reúnem uma dimensão estratégica. Significa isto que uma aliança só é estratégica quando possui impacto nos três domínios, ainda que, naturalmente, tenha sido classificada num só domínio (EIRIZ, 2002, p. 74).

Os autores Tachizawa e Rezende (2000) e Lorange e Roos (1996), comungam quanto aos recursos empresarias compartilhado: recursos organizacionais (compartilhamento de mão de obra; troca de produtos; entre outros); marketing; finanças; pesquisa e desenvolvimento; produção e recursos humanos. Algumas dessas alianças são feitas com a finalidade específica de atender exclusivamente as necessidades produtivas ou comerciais. Quando destinada a atender ao mercado, o processo de cooperação pode se tornar uma estratégia de diferenciação (TACHIZAWA; REZENDE, 2000). Partindo dos recursos alocados na cooperação é possível identificar três domínios de cooperação: comercial, técnico ou de produção e financeiro.

\subsubsection{Vantagens competitivas em acordos de cooperação}

A vantagem competitiva do acordo de cooperação deve também ser entendida a partir de um ponto de vista unificado. Muito frequentemente as empresas pioneiras de uma aliança estratégica não possuem compreensão realista e holística disso. (LORANGE; ROOS, 1996). Estes, reúnem especificidades estruturais e relacionais que permitem a obtenção de ganhos a partir de relações de cooperação orientada para competição como estratégia de aumentar a força competitiva (SOUZA, 2014). A união vai ao encontro de superação das limitações impostas pela própria cadeia de valor das empresas, bem como a competição do ramo da qual faz parte. Proximidade territorial, interdependência econômica e a dinâmica de aprendizagem constituem fatores coerentes à condução de cooperação entre empresas (MAGALHAES, 2009).

O resultado da cooperação entre as empresas é um dos principais focos dos estudos voltados às relações Interorganizacionais (BALESTRIN; VERSCHOORE, 2008). A principal fonte de competitividade da empresa está na capacidade de encontrar soluções criativas, tal como a diferenciação de produtos; novos processos; novos arranjos organizacionais; entre outros (MOZZATO, 2010).

A vantagem competitiva é representada pelo ganho perante os concorrentes, obtidos por meio de atividades que agreguem valor (NASCIMENTO, 2014). Essa ideia de cooperação como forma de potencializar a capacidade de competir, surgiu no final da década de 1990 (BALESTRIN; VERSCHOORE, 2008). Ainda segundo mesmos autores, em decorrência dessa percepção, governos e entidades privadas ao redor do mundo instituíram políticas de promoção e apoio a formação de alianças estratégicas. 


\section{METODOLOGIA}

Considerando que foram encontrados escassos trabalhos com esse mesmo objetivo, esta pesquisa se classifica como exploratória, pois visa conhecer as estratégias outrora ainda não contempladas em outros estudos. Também é de corte transversal, focado no determinado momento que as entrevistas foram realizadas, no período de março a abril de 2016.

A fim de alcançar os objetivos propostos neste estudo, recorreu-se ao estudo de caso único com múltiplas fontes de dados. Desse modo, foi analisado o grupo de MPEs alocadas no Complexo Empresarial Integrado do município de Tobias Barreto/SE. A coleta de dados deu-se por meio de entrevista com roteiro semiestruturado e abrigou 14 representantes de empresas.A análise do caso se deu por meio de Análise Qualitativa Básica (MERRIAM, 1998). Os critérios adotados para análise acompanham a seguinte ordem: (a) pré analise; (b) exploração do material; (c) tratamento dos resultados obtidos e interpretação.

\section{APRESENTAÇÃO E DISCUSSÃO DOS RESULTADOS}

A presente pesquisa teve como objetivo analisar as estratégias de inovação e as vantagens com- petitivas advindas de acordos de cooperação entre as empresas de produtos têxteis do Complexo Empresarial Integrado, situado no município de Tobias Barreto/SE. Tal empreendimento foi construído com base no modelo de sucesso dos distritos industriais italiano internacionalmente conhecido por manter aprendizagem e inovação constantes entre as empresas.

\section{O COMPLEXO EMPRESARIAL INTEGRADO}

Foi entregue ao município em 26 de junho de 2014 o Complexo Empresarial Integrado Governador Marcelo Déda, construído com 31 galpões para abrigar a produção têxtil do município de Tobias Barreto/SE. Além dos galpões, o complexo possui um Centro Vocacional Tecnológico (CVT) o qual foi outorgado a SEDETEC a missão de gerir e oferecer cursos profissionalizantes por meio do SENAI. O espaço também possui auditório para palestras, 82 boxes para comercialização e estacionamento para ônibus. Houve ainda a preocupação em criar um centro de serviços onde estariam CODISE, SEBRAE, SENAI, SEDETEC e BANESE.

As variáveis utilizadas no intuito de descrever as características empresas foram: ano de fundação, constituição jurídica, número de empregados, produtos fabricados e os meios de comunicação na empresa. No Quadro 4 podem-se observar alguns desses itens:

Quadro 4 - Características das empresas entrevistadas

Variável

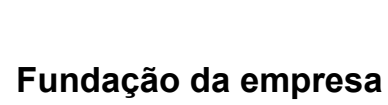

Fundação da empresa
Descrição

Números de respostas
Até 7 anos 4

8 anos 6

6

4 


\begin{tabular}{lcc}
\hline \multirow{2}{*}{$\begin{array}{l}\text { Número de } \\
\text { funcionários }\end{array}$} & Até 5 funcionários & 4 \\
\cline { 2 - 3 } & De 6 a 10 funcionários & 6 \\
\cline { 2 - 3 } & $\begin{array}{c}\text { Produtos de cama (colchas, lençol, edredons, } \\
\text { mosqueteiros) }\end{array}$ & 4 \\
\cline { 2 - 3 } Produtos fabricados & $\begin{array}{c}\text { Artigos para casa (capa de sofá, capa de almofada, } \\
\text { cortina, entre outros) }\end{array}$ & 13 \\
\cline { 2 - 3 } & Vestuário (roupa intima e de dormir) \\
\hline
\end{tabular}

Fonte: Elaborado pelo autor

A maior parte das pequenas empresas são relativamente jovens, dentre as 14 entrevistadas, 6 possuem oito anos de fundação. Curiosamente, Lima (2003) também identificou um grande número de empresas jovens no município, 75,6\% tinham até 12 anos de fundação e 29,3\% até 6 anos. Tal acontecimento condiz com o grande número de empresas abertas nos últimos dez anos, segundo secretaria municipal de finanças. Esse fato também demonstra que há poucos setores para investir no município, por isso o setor de confecções sempre terá empresas novas e jovens empreendedores. O resultado para a constituição jurídica dessas empresas foi unânime: firmas individuais, sendo três classificadas como microempresa e as onze demais empresas de pequeno porte.

\subsection{INOVAÇÃO}

Nas empresas deste estudo, as inovações foram adotadas na perspectiva de adquirir vantagens competitivas ou melhorias no desempenho empresarial. O Quadro 5 faz distinção das inovações adotadas pelos empreendedores.

Quadro 5 -Inovação adotada pelas empresas

Categoria

Variável
Inovação

Aperfeiçoamento dos produtos já existentes;

Criação de novos produtos; Inclusão de novos produtos; Inovação no processo.
Máquinas e equipamentos
Aquisição
Compra de máquinas modernas.

Tecnologia Aquisição Aquisição de software de gestão.

Fonte: Elaborado pelo autor 
Quando se refere a produto, foram constatadas maiores intenções em inovar. Entre as 14 empresas entrevistadas, nove afirmaram manter o hábito de aperfeiçoar ou modificar seu produto a fim de agradar o cliente. Entre as inovações realizadas destacam-se as seguintes: corte das peças; bainha; tecido utilizado; adaptação de colchas aos novos tamanhos de camas, entre outras. Essa estratégia de diversificação também foi encontrada nas empresas têxteis de Sergipe no estudo de Vaz e Barbosa (2014), onde o sistema de produção é usado para várias linhas, modificando constantemente as versões de produto. A melhoria nos produtos serviu a Empresa 3 como estratégia para maior alcance da clientela, conforme relatou:

Eu só trabalhava com produto 100\% algodão e, por isso, só conseguia atingir um público superior, que visasse qualidade. Foi quando observei a grande procura por produtos inferiores e decidi produzir com microfibra, cóton e poliéster, no intuito de alcançar outro público alvo e foi gratificante (Empresa 3).

Ainda sobre inovação, foi discutido sobre a criação de novos produtos. Para a Empresa1, essa estratégia permitiu ganhar mercado e obter lucros maiores em tempos difíceis. Ao observar as sobras de tecidos da produção de sua fábrica, essa empresa buscou usá-las em algo útil, no intuito de não as descartar, quando veio a ideia de criar as camas acolchoadas para cachorros, conforme depoimento a seguir:

A produção havia caído. Era início da crise e precisei demitir, vi as sobras de tecido no chão e pensei que pudesse aproveitá-las. Foi quando veio ideia de emendá-las para fazer uma cama de cachorro para o filhote do meu neto. Acredite, o produto fez tanto sucesso que hoje vendo bastante aproveitando minha sobra de tecido. Foi ótimo para mim e minha fábrica (Empresa 1).

A criação do produto se tornou um fator de melhoria e crescimento para a fábrica, bem como uma vantagem competitiva,razão da Empresa 1 ser o único a fabricá-lo. Em relação à inclusão de novos produtos, muitos a veem como estratégia de melhorar o desempenho da empresa de modo a atrair novos consumidores, levando ao aumento da receita. Das empresas, seis afirmaram incluir outros produtos a fim de aumentar sua carteira de clientes. Entre os produtos inclusos estão aqueles já fabricados por outras empresas do setor. Diferentemente, a Empresa 1 decidiu inovar mais uma vez, e incluiu em seus produtos a boneca de pano feita com retalhos oriundos da produção. Ao tomar essa atitude, recebeu o apoio da sua esposa, a qual ficou responsável pelos detalhes do design das bonecas e, assim, obteve vantagem competitiva nessa decisão.

Quanto à inovação no processo, trêsempresas buscaram essa estratégia no intuito de reduzir as perdas de tecido no momento do corte. Dois desses mudaram a maneira do corte, que antes era manual, transferindo esse processo para automatizado e, assim reduzindo de $25 \%$ a $16 \%$ de perdas. Felizmente, essa alteração do modo de corte passou a ser realizado após a percepção do funcionário recém-contratado observar uma forma onde se reduziria ainda mais as perdas.

A aquisição de máquinas modernas não é algo relevante aos empreendedores, pois, com as que já possuem, conseguem cumprir a demanda e 
alinhar qualidade ao produto de maneira satisfatória. Mesmo assim, duas das empresas adquiriram máquinas mais modernas nos últimos três anos. Com essa inovação, a Empresa 11 aperfeiçoou a produção de lençóis com lantejoulas, tornando esse processo mais rápido, uma vez que passou de manual para produção na máquina.

A aquisição de softwares foi representada por um número reduzido. Apenas três empresas investiram em programas de computador visando melhor organização nas tarefas da empresa. Curiosamente, em uma delas o programa está desativado, pois o único funcionário que sabia manuseá-lo foi demitido. No caso das outras duas empresas, foi possível melhorar o desempenho financeiro e aperfeiçoar o controle de estoque nas fábricas após a instalação do programa.

As principais fontes de informação sobre inovação (produtos, processos) usada pelos empreendedores são trazidas pelos fornecedores quando os visitam. Além dessa fonte, quatro empresas argumentaram participar de feiras de exposição do setor, a exemplo da Feira Nacional da Indústria Têxtil (FENIT). Reduzido número de empreendedores, ou seja, apenas dois afirmaram visitar outras empresas para se manter atualizados, bem como usar catálogos e revistas sobre as tendências.

Buscou-se identificar as estratégias de inovação adotadas pelas empresas. As inovações em produto foram divididas entre aperfeiçoamento, criação, melhorias e inovação do processo sendo citada por nove empreendedores afirmando que as praticam. As inovações em relação à aquisição de máquinas e equipamentos existem minimamente, uma vez que a produção não depende de nada tão tecnológico ou moderno. O investimento em tec- nologia é algo desejado, porém, visto como último plano por ter custos relativamente altos.

\subsection{ALIANÇAS ESTRATÉGICAS}

Nas empresas do Complexo Empresarial Integrado de Tobias Barreto, foram encontrados três casos diferentes de acordos. No primeiro caso, a Empresa 1 procurou concorrentes com capacidade de produção insuficiente e que não conseguiam atender aos pedidos de consumidores. Ele solicitou a esses concorrentes o encaminhamento de parte da produção para sua empresa. Esse fato aconteceu devido à diminuição de demanda na fábrica desse empreendedor, que permaneceu três meses, em 2015, de portas fechadas. Consequentemente demitiu metade dos seus funcionários. Foi à busca por uma estratégia que o levou a tomar a decisão de formar parceria com um concorrente, conforme seu depoimento:

Como sei que muitas fábricas aqui fazem hora extra eu procurei alguns concorrentes e me ofereci a produzir o que eles não conseguiam em tempo de expediente. Mesmo ganhando minimamente, eu consegui permanecer em atividade, produzindo minha demanda e o que eu pegava fora; assim, não foi preciso fechar nem demitir mais ninguém (Empresa 1).

Este tipo de cooperação é definido como acordo de produção conjunta, caracterizada por alianças de cunho técnico/produção (EIRIZ, 2002). Das empresas analisadas, apenas duas concordaram em manter esse acordo. Para a empresa solicitante foi uma alternativa de manter-se ativo no mercado; 
para as demais empresas, foi a chance de diminuir custos com horas extras e evitar atrasos nas entregas de pedidos. Tal estratégia também foi apontada como satisfatória no estudo de Jardim (2014), onde as empresas de automação industrial em São Paulo viram que sozinhas não conseguiriam cumprir com seus compromissos. Contudo, a parceria acabou alavancando o negócio dos empreendedores visto que o acordo também visava criação de novas oportunidades, troca de experiência e estreitamento do relacionamento entre os cooperados.

O segundo caso encontrado, envolve quatro empresas e constitui-se como um acordo familiar. São elas: Empresa 6, Empresa 7, Empresa 8 e mais uma empresa fora do Complexo Empresarial Integrado. Além de central de compras do tipo comercial, esse acordo se constitui de uma aliança de investigação e desenvolvimento da tipologia técnico/produção cujo objetivo é a inovação e redução de custos (EIRIZ, 2002). O objetivo do acordo é tentar diminuir os custos da empresa no intuito de conseguir uma margem de lucro maior, visto que afirmaram não conseguir praticar um preço que julgam justos devido à concorrência.

Mais que esse objetivo, as empresas se uniram com o propósito de buscar estratégias que as permitissem competir, conforme citou a Empresa 7: “... quatro cabeças pensam melhor que uma, não é? (Risos) ..." O acordo tem como foco integração com fornecedores, propondo a compra de matéria-prima com preço mais competitivo. Além dessa realidade, essas empresas mantêm sempre contato transferindo conhecimento e aprendizado, tal como buscam atualizar-se a fim de permanecerem informadas sobre as tendências e novidades do setor. Pode-se classificar a aprendizagem como sinér- gica, onde os esforços em comum geram inovações nas empresas principalmente no fator produto.

A troca de informações e o compartilhamento de aprendizado entre as empresas foram colocados em evidência nos acordos de cooperação dos estudos de Bortolaso (2008) nas lojas de artigos esportivos no Rio Grande do Sul e Nascimento (2014) nos supermercados de Parobé/RS. Nesse acordo precisamente, houve trocas de experiências gerencias e contratação de serviços conjuntos a exemplo de segurança patrimonial e poda do jardim das fábricas. Outro fator que permitiu menor custo para as empresas em conformidade com a Empresa 8:

Na hora de contratar esses serviços temos de ser muito esperto, pois tem gente que cobra caro. Cada uma de nós pagaria cerca de $R \$ 150,00$ reais a mais nestes serviços caso fosse contratado individualmente. Nosso acordo nos permitiu ainda essa economia (Empresa 8).

Com uma história parecida, o estudo de Nespolo (2014) apresentou uma rede de empresas que era originalmente familiar. Com o passar dos anos, no intuito de concorrer com as empresas maiores, a rede se expandiu e atualmente conta com mais de 70 supermercados no Rio grande do Sul. As vantagens competitivas alcançadas pela rede são: maior escala de mercado; geração de soluções coletivas; redução de custos e riscos; acúmulo de capital social; aprendizagem coletiva; inovação colaborativa.

O terceiro caso do acordo das empresas no Complexo Empresarial Integradotrata-se da aliança que envolve maior número de empresas: sub- 
contratação, neste tipo uma empresa subcontrata a outra parte do seu processo de produção. Deste modo, cada um dos parceiros desenvolve trabalho diferente (EIRIZ, 2002). Essa cooperação envolve 12 das empresas entrevistadas e pequenos produtores, geralmente informais, que fazem trabalho manual em casa. Esse trabalho terceirizado normalmente são colchas, lençóis e fronhas, que são repassados pelas fábricas para serem pintadas, ou bordadas retornando à fábrica apenas para acabamento. Cada empresa que opta por essa aliança tem entre 10 e 20 cooperados. O foco é estritamente financeiro, visando à diminuição de custo dos produtos. Essa decisão diminui o número de empregados registrados e, consequentemente, as despesas com funcionários e custos trabalhistas. Alinhados com o que trazem Balestrin e Verschoore (2008) em sua pesquisa, ou seja, a ênfase na redução de custos é vista com maior ênfase pelos acordos de cooperação mais recentes que, em geral, buscam ganhos imediatos.

A aliança com um concorrente não deve ser usada para limitar essa concorrência. Não importa com quem a empresa esteja trabalhando; há outras que estão reunindo forças para ir em frente. Assim, como no caso de outras alianças, a cooperação com um concorrente deve acentuar as competências de cada empresa em separado (LEWIS, 1992). Daí o grande desafio: fazer com que os concorrentes cooperem.

Além de estar fundamentada em uma ideia de negócio viável e uma estratégia global realista, uma aliança estratégica deve basear-se em cooperação mútua entre as partes envolvidas. É necessário criar um clima de confiança e entendimento mútuos, porque os sócios estão entrando em uma aliança pela primeira vez (LORANGE; ROOS, 1996).

\subsection{VANTAGENS COMPETITIVAS}

O Quadro 6 buscou evidenciar as vantagens competitivas alcançadas pelas empresas nos acordos de cooperação, cerne desta pesquisa, utilizando o modelo desenvolvido por Balestrin e Verschoore (2008), expondo as variáveis definidas como fonte de vantagens competitivas nos referidos acordos de cooperação. Cabe ressaltar que apenas algumas das variáveis do modelo utilizado foram encontradas no estudo de Tobias Barreto as quais foram relacionadas a cada acordo.

Quadro 6 - Vantagens competitivas em acordos de cooperação (conclusão)

$\begin{array}{ccc}\text { Ganhos competitivos } & \begin{array}{c}\text { Variáveis do modelo de Balestrin e } \\ \text { Verschoore }\end{array} & \begin{array}{c}\text { Variáveis encontradas nas empresas } \\ \text { analisadas }\end{array}\end{array}$

$\begin{array}{lll}\text { Aprendizagem e } & \text { Disseminação de informações; } & \text { Disseminação de informações (04); } \\ \text { inovação } & \text { Inovações coletivas; } & \text { Inovações coletivas (04). } \\ & \text { Bench marketing interno e externo; } & \end{array}$

Atividades compartilhadas;

Confiança em novos investimentos;

Redução de custos Complementaridade;

Facilidade transacional;

Atividades compartilhadas (04);

Produtividade. 
Limitação do oportunismo;

Ampliação da concorrência;

\section{Relações sociais}

Acúmulo de capital; Laços familiares;

Reciprocidade;

Coesão interna.
Reciprocidade (03).

Fonte: Adaptado de Balestrin eVerschoore (2008)

As variáveis do modelo usado em questão serão descritas utilizando o encontrado na pesquisa. O número ao lado de cada variável é a quantidade de empresa agraciada com a vantagem adquirida por meio da cooperação. O poder de barganha se refere às compras de matéria prima realizadas com preço reduzido para as empresas engajadas nos acordos. Esta variável é o principal foco quando surge a intenção de parcerias entre as empresas. Quanto à credibilidade, pode-se sustentar que o setor têxtil do município ganhou visibilidade diante de sua expansão, atraindo ações desenvolvidas para seu fortalecimento pelos órgãos de apoio às empresas. Tais vantagens também foram encontradas nos estudos de Souza (2014), Nespolo (2014) e Fernandes (2014).

A existência de representatividade, seja para qualquer setor da economia, torna-se importante por buscar conseguir melhorias e oportunidades para as empresas. Por meio da existência da Cooperativa de Negócios do estado de Sergipe (COOPNE), citada por Zambrana e Teixeira (2012) como Governança Coorporativa local, o setor têxtil teve por determinado tempo um órgão que os representasse diante dos governos estadual e municipal. Cabe ressaltar que atualmente a cooperativa está desativada. Sindicatos também representam os anseios empresariais diante de órgãos responsáveis pelo desenvolvimento das empresas. O sindicato dos trabalhadores da indústria têxtil (SINDITEXTIL), segundo a ótica dos empreendedores, realiza um trabalho insatisfatório por se fazer presente apenas para recolhimento de contribuição sindical. A existência de representatividade foi importante para as empresas da rede de empresas de tecnologia na região metropolitana de São Paulo analisadas por Tálamo (2008) e o arranjo produtivo de pedras preciosas em Soledade/RS estudadas por Mozzato (2010) alcançarem vantagens competitivas.

Ainda que seja desafio para as empresas de pequeno porte conseguir financiamentos, os empreendedores usufruíram de garantia ao crédito tendo como parceiro o Banco do Brasil. Essa vantagem foi conseguida por meio dos esforços da COOPNE, que torna claro a importância da representatividade e dos laços, cada vez mais estreitos, entre empreendedores. Os supermercados da cidade de Parobé/RS analisados por Nascimento (2014) obtiveram o acesso ao crédito em consequência da cooperação existente entre eles.

A variável produtividade foi contemplada com o acordo de produção, outrora não conseguida em tempo hábil, a matéria prima era repassada para outra empresa integrante do Acordo. Nessa transação, as horas extras diminuíram e os pedidos foram atendidos. Em continuidade, a redução de custos também foi constatada como atividades compartilhadas entre as empresas. Neste caso, o acordo de cooperação familiar, garantiu menor valor a ser pago nas 
contratações de prestação de serviços referentes à segurança patrimonial e jardinagem.

Especificamente na rede familiar, a confiança e proximidade entre as empresas permitiram 0 compartilhamento de informações. Consequentemente, criou-se um ambiente de aprendizagem, seja da experiência teórica advinda da Empreendedora 6, como da experiência da Empreendedora 5. Tal acordo permitiu às empresas inovações coletivas, principalmente concretizadas nos produtos, que foram adaptados como forma de diferenciação dos concorrentes. Semelhantemente, a rede de lojas esportivas analisada por Bortolaso (2008) e os empreendedores estudados Jardim (2014) ratificaram que essas variáveis foram importantes para aprimoramento e desempenho das redes de empresas.

A reciprocidade existiu com os acordos de produção, típicos do terceiro caso. Houve simetria entre empresas e produtores, ou seja, as empresas diziam: preciso de você; os produtores informais pensavam: vocês precisam de mim. A partir daí existiu coesão de objetivos entre as partes interessadas e início de uma cooperação profícua. Basicamente o compartilhamento da produção para trabalhadores informais garantiam as empresas menor custo de mão de obra e manutenção da produtividade.

Apesar da obtenção de vantagens competitivas nos acordos de cooperação, a concorrência desleal ainda impede o sentimento de confiança entre as empresas de produtos têxteis do Complexo Empresarial Integrado. Essa desconfiança impede as empresas de desenvolver atividades que proporcionem vantagens competitiva superiores (força de mercado, prospecção de novas oportunidades, confiança em novos investimentos). Como exemplo disso, Mozzato (2010) afirmou que a confiança nos parceiros estra- tégicos foi primordial para a prosperidade da rede e desenvolvimento econômico do setor.

No estudo de Chagas, Pinto, Santo (2005) foi encontrado, entre as empresas têxteis do município de Tobias Barreto, significativo percentual (33\%) que afirmaram não achar importante a promoção de ações cooperativas. Após alguns anos, Feitosa (2009) afirmou que a cooperação vinha se intensificando entre as empresas, porém ainda pouco significante. O objetivo do estudo dos referidos autores, foi encontrar características de APL (arranjo produtivo local) em Tobias Barreto, porém tal resultado não ocorreu, pois não encontraram formas de cooperação e aprendizado eficaz entre as empresas existentes no município.

Mesmo com o passar do tempo, ainda se observa reduzida cooperação entre as empresas. Zambrana e Teixeira (2012) concluíram, que em virtude disso, as empresas ainda não se beneficiam das economias de escala. A falta de confiança existente e o medo pelo oportunismo têm impedido que essas empresas se estruturem como um Arranjo Produtivo Local. Além disso, a governança coorporativa citada pelas autoras Zambrana e Teixeira (2012) a COOPNE encontra-se desativada.

Vale ressaltar que, apesar de pequenos benefícios obtidos por meio da cooperação, os empreendedores julgaram se valia à pena permanecer no acordo. Existe a possibilidade que o amadurecimento desses acordos os façam enxergar outras oportunidades e, com essa atitude, possam se beneficiar de vantagens superiores. A seguir alguns depoimentos sobre o assunto:

Eu consigo diminuir o preço da aquisição de minha matéria prima, o que me leva a ter um pou- 
co mais de lucro. Além da redução de custos na contratação de prestação de serviço. Seria meIhor poder usufruir mais, eu acredito que esse quadro vai mudar (Empresa 6).

Eu consigo lucrar um pouco mais visto que a margem de lucro aqui é pequena por causa da formação de preço de alguns concorrentes. Em tempos de baixa demanda, eu produzo o que sobra das minhas parceiras, que me faz continuar ganhando (Empresa 8).

Para mim é ótimo, mesmo que eu não tenha produção eu consigo fazer o que sobra dos meus parceiros. Isso me mantém ativo mesmo sem vendas, é um lucro menor mais é lucro (Empresa 1).

Apesar de apenas algumas variáveis do modelo ter sido verificada na cooperação entre as empresas, estas ocorrem de forma isolada. O modelo sugere que todas pratiquem as mesmas atividades, no intuito de conseguirem os mesmos benefícios, a fim de existir a satisfação mútua (BALESTRIN; VERSCHOORE, 2008).

Cabe ressaltar que a problemática central desse estudo foidescrever as vantagens competitivas das empresas sejam em estratégias individuais ou em acordos de cooperação. O setor têxtil de fabricação do município tem crescimentoconstante, segundo informações da Secretaria Municipal de Finanças de TobiasBarreto/SE. Certamente esse desejo de investir abrindo uma nova fábrica ou loja é motivado por herança cultural passada de geração a geração.

Consequentemente, esse fato alimentou a concorrência entre as empresas do setor têxtil. Em virtude disso, estas se viram obrigadas a diminuir o preço de venda no intuito de concorrer com o praticado pelos seus concorrentes. É obvio que os custos de um produtor informal não chegam próximos aos de uma fábrica. Por esse motivo, diminuir o preço de venda não foi o suficiente para as empresas manterem seu nível de lucro e investimento.

Neste cenário, surgiram os primeiros acordos de cooperação. Para as empresas, foi uma alternativa usada a fim de diminuir os custos, repassando as atividades primárias como pintura e costura de produtos para trabalhadores autônomos. Além disso, outras decisões foram tomadas por algumas empresas nos seguintes aspectos: diminuir o tamanho do corte dos lençóis, substituir os tecidos pelos mais baratos; atacar os concorrentes no intuito de tomar seus clientes, entre outros. Essas atitudes desencadearam rivalidades e tornou a concorrência ainda mais acirrada.

\section{As vantagens competitivas encontra-} das na cooperação ainda não são eficazes a ponto de alavancar as MPEs, ou complementá-las com aprendizado advindo de parceiros. Pode-se dizer que, na verdade, as empresas ainda não descobriram o verdadeiro sentido de juntar esforços para aprimoramento conjunto. Até agora, a cooperação só existe a fim de obter benefícios individuais e quando essas vantagens diminuíam ou cessavam, ocorre à mortalidade do acordo.

\section{CONSIDERAÇÕES FINAIS}

Os objetivos pretendidos neste estudo foram alcançados. Foi possível conhecer os acordos ainda embrionários existentes entre as empresas, bem como as vantagens competitivas alcançadas usando a estratégia colaborativa. Os resultados encontrados, levam a crer que as empresas do Com- 
plexo Empresarial Integradoutilizam estratégias competitivas principalmente para buscar sobreviver ao ambiente de concorrência acirrada. Essa preocupação excessiva faz com que estas empresas gastem muito tempo tentando competir e, consequentemente, utilizam poucas estratégias de crescimento e aprimoramento.

Tendo como pretensão contribuir com uma análise acerca da situação das vantagens competitivas advindas dos acordos de colaboração entre as empresas do Complexo Empresarial Integrado, as conclusões encontradas podem servir como norteador para futuras ações no município. A estratégia em acordos de cooperação, quando efetivamente praticada, pode propiciar as empresas engajadas os seguintes benefícios: combate as práticas desonrosas e evitar concorrência desleal; participação em feiras e atividades conjuntas que proporcionem redução de custos. Todas essas variáveis foram apontadas como atividades que os empreendedores gostariam de compartilhar. Neste aspecto encontra-se a contribuição dessa pes- quisa ao município, uma vez que se pretendeu trazer alternativas cabíveis ao desenvolvimento das empresas analisadas.

Finaliza-se salientando que seria interessante o acompanhamento das atividades pelos setores de apoio ao desenvolvimento do município. Novas tecnologias requerem mão de obra qualificada e, para esse propósito, o Centro de Serviços foi construído e continua fechado sem oferta de cursos profissionalizantes. Uma possível solução seria a formação de representatividade pelas empresas no intuito de cobrar melhorias e o início das atividades dos órgãos no Complexo Empresarial Integrado pesquisado. Sugere-se o envolvimento do SEBRAE com o apoio à estruturação e formação de uma rede de cooperação, tal como feito entre as pizzarias da região metropolitana de São Paulo estudado por Tálamo (2008). À Secretaria Municipal de Indústria, Comércio e Trabalho caberia a continuidade dos serviços ofertados e, se possível, a criação de uma governança coorporativa uma vez que essa forma de gestão é bem vista pelos empreendedores.

\section{REFERÊNCIAS}

AMORIM, A. A.;ANDRADE JUNIOR, H. Avaliação de Projetos de Sustentabilidade de Inovação Tecnológica por Empresas Industriais Brasileiras. Revista Gestão Industrial. Ponta Grossa-PR, ISNN 1808-0448, v.7, n.3, p.158-178, 2011.

ARAÚJO, R. M. Vantagem Competitiva em um APL de Móveis. Revista Pretexto. Belo Horizonte, ISSN. 1517-672, v.15, n.4, p.64-82, out/dez, 2014.

BALESTRIN, A.;VERSCHOORE, J. R. Ganhos Competitivos das Empresas em Redes de Cooperação.
Revista de Administração (RAUSP). São Paulo, v.1, n. 1, art.2, jan/jun, 2008.

BORTOLASO, I. V. Vantagens Competitivas Observadas em uma Rede de Cooperação para Comercialização de Artigos Esportivos. Revista Gestão da Produção, Operações e Sistemas (GEPROS). Ano 4, n.2, p.37-49, abr/jun, 2009.

BRASIL, PORTAL. Sobrevivência e Mortalidade.

2012. Disponível em: <http://www.brasil.gov. 


\section{REFERÊNCIAS}

br/economia-e-emprego/2012/02/sobrevivencia-e-mortalidade>. Acesso em: 10 de set. 2015

CASADEI, M. C. B.; FARAH, O. L.; GIULIANI, A. C. Alianças Estratégicas como Ferramenta para Pequenos Negócios. Revista Organizações em Contexto (ROC). Ano 1, n.1, jun, 2005.

CHAGAS, G. M.; PINTO, M. M.; SANTOS, C. B. Arranjos Produtivos Géstion Tecnológica. Anais... Congresso Latino Ibero-Americano de Gestão Tecnológica(ALTEC). Salvador, 2005.

CHRISTENSEN, C. M. O Dilema da Inovação: quando novas tecnologias levam empresas ao fracasso. São Paulo: M.Books do Brasil Editora, 2012.

COSTA, G. H. Cooperação entre Micro e Pequenas Empresas de Hospedagem como Fonte de Vantagem Competitiva: estudo dos albergues de Belo Horizonte- MG. Revista Turismo -Visão e Ação. V.16, n.1, abr, 2014.

EIRIZ, V. Proposta de Tipologia sobre Alianças Estratégicas. Revista de Administração Contemporânea (RAC).Curitiba, On-lineversionISSN 1982-7849, v.5, n.2, mai/ago, 2001. Disponível em: $\quad<h t t p: / / w w w . s c i e l o . b r / s c i e l o . p h p ? s c r i p t=s-$ ci_arttext\&pid=S1415-65552001000200004>. Acesso em: 17 de jul. 2016.

FEITOSA, C. O. Aglomerações Industriais como Fator Desenvolvimento Regional: um estudo de caso no nordeste brasileiro. Edição eletrônica, 2009.Disponível em: <http://www.eumed.net/ libros-gratis/2009a/521/indice.htm>. Acesso em 10 mai. 2015.
FERNANDEZ, I. C. Fatores Competitivos em Redes de Cooperação Inter Organizacionais: estudo em uma rede do setor de materiais de construção. Trabalho de Conclusão de Curso, UFPB, 2014.

GOMES, R. R.; BARBOSA, J. D. Tecnologia da Informação e o Processo de Gestão da Inovação: um estudo de caso de uma empresa de Serviços de TI em Aracaju/SE.Dissertação de Mestrado em Administração, UFS, 2012.

JARDIM, D. A. Um Estudo das Redes Estratégicas como Fator de Vantagem Competitiva para o Empreendedorismo. Anais...VIII Encontro de Estudos sobre Empreendedorismo e Gestão de Pequenas Empresas (EGEPE). Goiânia, 2014.

LEWIS, J. Alianças Estratégicas: estruturando e administrando parcerias para o aumento da lucratividade. São Paulo: Pioneira, 1992.

LIMA, M. E. Comercio de confecções e bordados como atrativo turístico: o caso do município de Tobias Barreto. Dissertação de mestrado, UFS, 2003.

LORANGE, P.; ROOS, J. Alianças Estratégicas: formação, implementação e evolução. São Paulo: Atlas, 1996.

MAGALHAES, J. M. Vantagens Proporcionadas a Pequenas e Médias Empresas por Meio da União em Redes de Cooperação no Contexto Venture Capital. Revista de Administração Contemporânea (RAC). Curitiba, v.13 n.4, art.4, p. 583603, out/dez, 2009. 


\section{REFERÊNCIAS}

MERRIAM, S. B. Qualitative Research and Case Study Applications in Education. San Francisco: Jossey-Bass, 1998.

MINTZBERG, H.; LAMPEL, J.; QUINN, J.B.; GOSHAL, S. O Processo da Estratégia: conceitos, contexto e casos selecionados. Porto alegre: Artmed, 2007.

MOZZATO, A. R. Relações Inter Organizacionais: cooperação e competição como vantagem competitiva para o Arranjo Produtivo de Gemas e Pedras Preciosas de Soledade. Anais...VI Encontro de Estudos Organizacionais da ANPAD (ENEO). Florianópolis, 2010.

NASCIMENTO, R. B.; SCHREIBER, D. Análise Compreensiva de Benefícios Proporcionados para as Empresas de Pequeno Porte através de Rede de Cooperação. Anais... VIII Encontro de Estudos sobre Empreendedorismo e Gestão de Pequenas Empresas (EGEPE). Goiânia, 2014.

NESPOLO, D. Vantagens Competitivas de Pequenas e Médias Empresas com a Participação em Redes de Cooperação: o caso do mercado Tutto. Revista de Empreendedorismo e Gestão de Pequenas Empresas (REGEPE). Seção casos de ensino, v.3, n.2, p.145160, 2014.

PACAGNAN, M. N. Alianças Estratégicas e Redes Colaborativas como Alternativa Competitiva para o Pequeno Varejista: um estudo comparado. Revista de Gestão (REGE). São Paulo, v.13, n.especial, p.19-30, 2006.
PORTER, M. Competição: estratégias competitivas essenciais -a vantagem competitiva das nações. Rio de janeiro: Campus. 1999.

SACRAMENTO, P. M.; BARBOSA, J. D. Inovação em Pequenas e Médias Empresas:garantia de sucesso e longevidade dos negócios?Dissertação de Mestrado em Administração, UFS, 2012.

SEBRAE. Pequenas Empresas Perderam 49,7 mil Empregos em Outubro. Agência SEBRAE de notícias, 2015. Disponível em: <http://revistapegn.globo.com/ Empreendedorismo/noticia/2015/11/pequenas-empresas-perderam-497-mil-empregos-em-outubro. html>. Acesso em 18 mai. 2016.

SEBRAE. Taxa de Sobrevivência das Empresas no Brasil. Coleção de estudos e pesquisas, 2011. Disponível em: <http://www.sebrae.com. br/Sebrae/Portal\%20Sebrae/Anexos/Sobrevivencia_das_empresas_no_Brasil_2011.pdf>. Acesso em 13 mai. 2015.

SILVA NÉTO, A. T.; TEIXEIRA, R. M. Mensuração do Grau de Inovação de Micro e Pequenas Empresas: estudo em empresas da cadeia têxtil-confecção em Sergipe. Revista de Administração e Inovação (RAI). ISNN 1809-2039, v.8, n.3,p.205-229, jul/ set, 2011.

SOUZA, A. R. Cooperação no APL de Santa Rita do Sapucaí. Revista de Administração Mackenzie (RAM). São Paulo, v.16, n.1, p.157187,jan-fev, 2015. Disponível em: <http://dx.doi. org/10.1590/1678-69712015/administração>. Acesso em: 28 abr. 2015. 


\section{REFERÊNCIAS}

TACHIZAWA, T.; REZENDE, W. Estratégia Empresarial: tendência e desafios - um enfoque na realidade brasileira. São Paulo: MAKRON books, 2000.

\section{TÁLAMO, J. R. Formação e Gestão de Redes} de Cooperação Empresarial. Departamento de Engenharia da Produção. Escola Politécnica da Universidade de São Paulo. São Paulo: Ed.rev. J.R. Tálamo, 2008.

TAVARES, M. C. Gestão Estratégica. 2 ed. São Paulo: Atlas, 2005.
VAZ, V. H.; BARBOSA, J. D. Cooperação Inter Organizacional para o Desempenho das Pequenas e Médias Indústrias dos Segmentos Têxteis e de Confecção de Sergipe. Anais...VIII Encontro de Estudos sobre Empreendedorismo e Gestão de Pequenas Empresas (EGEPE). Goiânia, 2014.

ZAMBRANA, A.A.; TEIXEIRA, R. M. Governança e Cooperação no Desenvolvimento de Arranjos Produtivos Locais: estudos de casos múltiplos nos Arranjos Produtivos Locais de Sergipe. Anais...VII Encontro de Estudos sobre Empreendedorismo e Gestão de Pequenas Empresas (EGEPE). Florianópolis, 2012. 